Review

\title{
Endeavors in the Area of Hair Care-Chemical Aspects of Hair Care Processes and Products
}

\author{
Leszek J. Wolfram \\ San Francisco, CA 94109, USA; ljmaw@aol.com; Tel.: +1-415-292-3570 \\ Academic Editor: Won-Soo Lee \\ Received: 11 May 2016; Accepted: 24 June 2016; Published: 16 August 2016
}

\begin{abstract}
The paper focuses on historical review of explorations and progress in the field of hair care. The descriptive theme of the survey is accompanied by references to specific investigations of the structure and physico-chemical properties of hair that are essential for evolving of novel processes and products.
\end{abstract}

Keywords: historical review; hair care; hair; hair reactivity; hair properties

\section{Introduction}

Throughout recorded history, hair has always been an important element of personal adornment. From the beautifully crafted beard curls of the Assyrian kings, through elegant hair styling of the ladies of oriental courts to carefully coiffured wigs of European nobility, hair was there to be shown, admired and envied. Over the years, what had been a privilege of the affluent few has become a consuming passion of many. The explosive growth of the hair market since the middle of the twentieth century was the result of technological progress and deep socioeconomic changes combined with an increasing focus on personal aesthetics and assisted by affordability of the products. Attempts to satisfy the needs of the consumers and the drive for competitive advantage has led to a variety of grooming aids and products - shampoos to cleanse the hair, conditioners to make it soft and easy to comb hair sprays to keep hair in a desired shape, hair colorants and permanent waves and straighteners to impart to hair properties it did not have.

This presentation is an attempt to provide a historical retrospective into the explorations and accomplishments in the field of the hair care. As such, it is by necessity, descriptive.

On occasions, frequent enough, I hope, some fundamental issues relevant to the specific products or their efficacy will be addressed and discussed in some depth.

\section{Early Times}

After what must have been seen as an infinity of quiescence and inertia, things began to change. Figure 1 offers a glimpse of our Universe barely four hundred thousands years after the Bing Bang. Not a very promising picture, yet few billions years later and just over forty thousand years after the "out of Africa" migration, in a small camp somewhere in Mesopotamia, a young woman was squatting near a large puddle left over by previous night's rain. She might have been cooking some simple meal or just resting for a while. She glanced at the puddle and saw a reflection of her face. She turned her head away, but then glanced at her reflection again. She shook her head but her long, almost straight hair seemed to be stuck together. She grimaced and murmured to herself "I've got to do something with my hair" —and that how it all had begun! Soon mirrors made of glossy volcanic rock (obsidian) replaced the water puddles, combs crafted from reeds or wooden twigs came into use, and as the bronze age downed on, the scissors made their first appearance (Figures 2 and 3). 


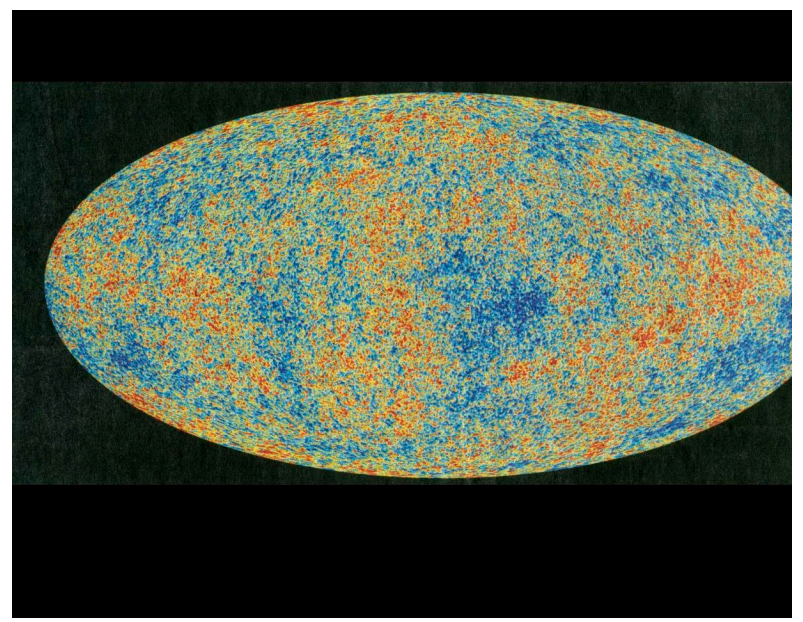

Figure 1. Image of the Universe 400,000 years after the Big Bang.

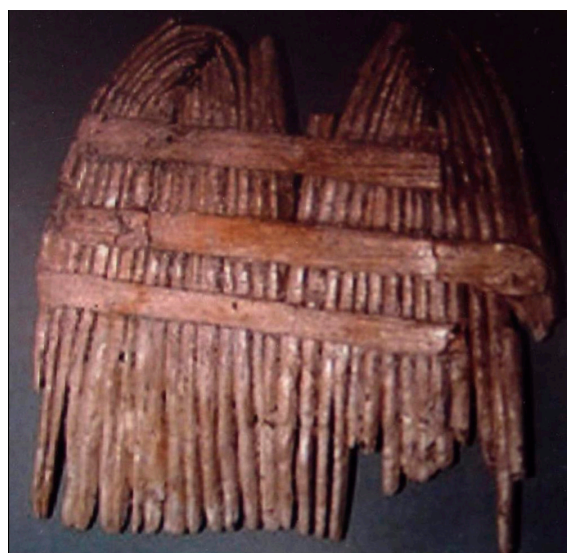

Figure 2. Comb made from wooden twigs.

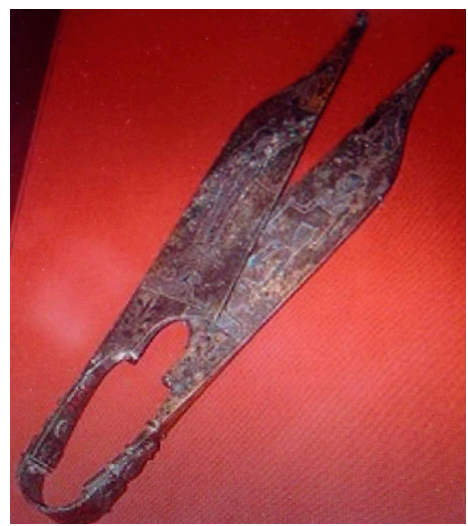

Figure 3. Scissors from the bronze age.

Clearly the stage was being set for styling and that was what followed, particularly in the Middle East, by hair curling and tinting. It is amazing how the hair care skills developed so well ahead of understanding the fundamentals of processes that were practiced. Our ancestors must have been keen observers of hair response to moisture and heat and exploiting those observations in developing effective procedures and inventing appropriate implements. As an example may serve the elaborate curls of Assyrians (Figures 4 and 5) who utilized wet clay slats to roll the hair on and letting it dry in the hot sun. 


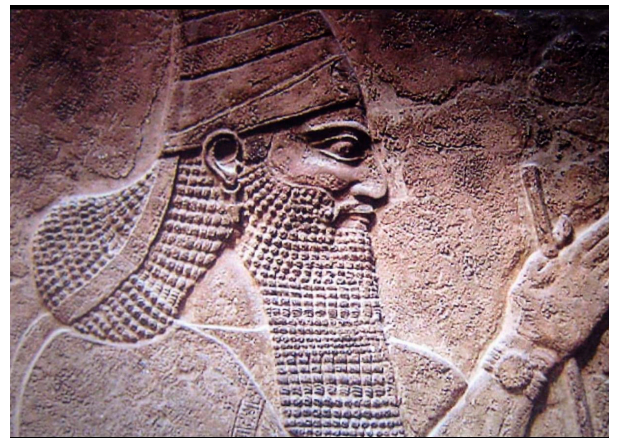

Figure 4. Curled hair and beard of an Assyrian nobleman.

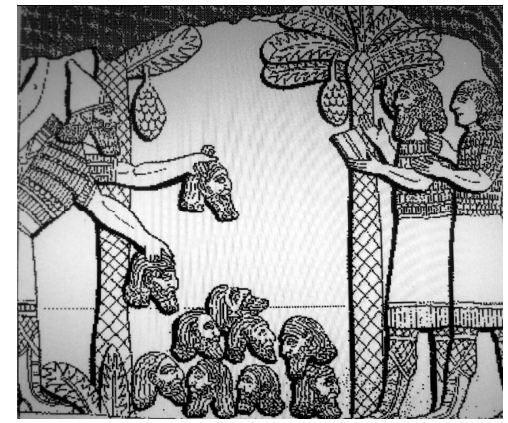

Figure 5. Counting the heads of the fallen warriors.

Even then there was a demand for wigs-the rolling technique was similar but the drying step was carried out in heated chambers. It is of interest to note that in contrast to the Middle East Empires hair was almost never curled in China or Japan where, rather, elaborate hair arrangements were routine at the courts of the emperors (Figure 6).

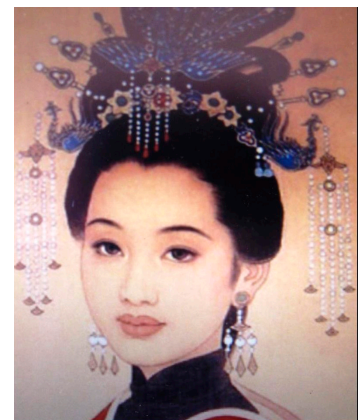

Figure 6. Chinese noblewoman.

Apparently, the gorgeous beauty of this thick, black and lustrous hair was not to be interfered with by fiddling with its geometry. This attitude has clearly survived until today and it is seldom that one can see an Asian with a curly hair. It is worth commenting that it was a mutation of the ectodysplasin A receptor (EDAR) [1] gene some thirty five thousand years ago in the Central China that conferred these distinct and highly desirable characteristics to East Asians. This mutation also bestowed their scalp with more numerous sweat glands but extracted a price from women in form of their smaller breasts.

Over the millennia, hair styling has continued to be the dominant factor of hair beautification assisted by oils and powders for its enhancement and its stability. A woman's crowning glory 
aggrandized by combination of curls, braids, pleats and puffiness in Marie Antoinette's style flourished unabated with a brief pause in Middle Ages when hair, on account of church's teaching on sin and temptation, had found a temporary refuge under caps and scarves. An old adage that what you do not see is even more tempting that what you do was clearly lost on the fathers of the church as even a simple cover can tell you of the beauty it hides (Figure 7).

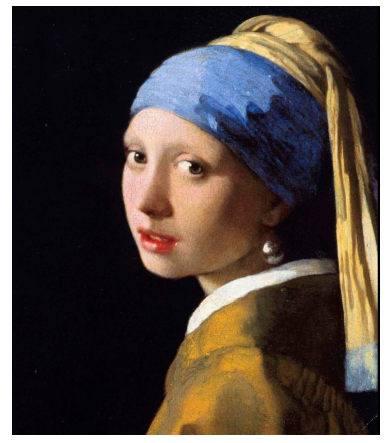

Figure 7. Young girl with a head cover.

It was clearly obvious to our ancient friends that it would be highly desirable to further embellish the styled hair by enhancing its appearance with a touch of the color. Nature was there ready to help. Dyes extracted from shell fish were complemented with those derived from crushed insects, grounded nuts and berries and charred ant eggs. However, the hair of that time, and as it was for thousands years before was predominantly black and thus the imparted color effects must have been minor. Things were to change as the northward spread of the population and evolution's tenets of natural selection caused the skin and hair of migrants to lighten (Figures 8 and 9).

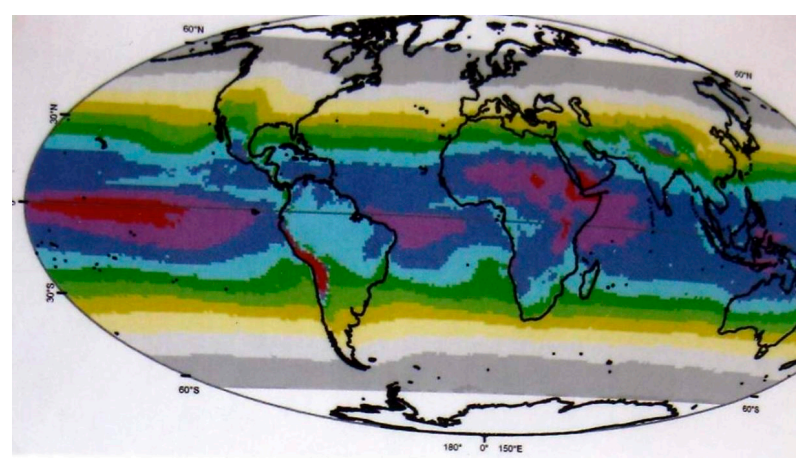

Figure 8. Global distribution of the UV component of sunlight.

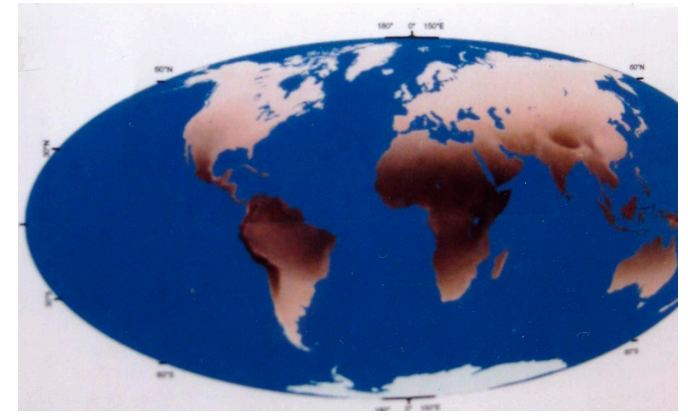

Figure 9. Global distribution of the dark-skinned population. 
This has become particularly apparent to Romans in their conquest of Northern Europe. The blond hair of captured Germans and Celts did not escape the attention of Roman ladies as they watched the "barbarians" being led through the streets of Rome. The appeal of the blond hair was so overwhelming that in many instances the hair of the captured women and men was cut off and made into wigs to be worn by some lucky Roman matrons. Allusions to cases of blue eyes apparently seen in some prisoners should not be left unanswered. Tempting as such proposition may seem to be, the blue eyes did nor originate in the frosty North. Some six thousand years ago an individual was born in the Black Sea region with a mutation in the OCA2 gene that codes for the protein producing melanin in the iris. He or she is the single common ancestor of people with blue eyes [2]. Therefore, look around, you may find some distant cousins right in here!

\section{Tinkering with Color}

Although the collapse of the Roman Empire ended the abundant supply of the blond hair, the fascination with the "golden" hair has remained strong, blossoming again with the arrival of the Renaissance. The gorgeous Italian blondes have been forever memorized in the paintings of Botticelli, Tizian, Tintoretto and Veronese. While this color preference might have reflected artistic license it appears that it has more to do with the fashions and notions popular with the 16th century Venetian nobility, especially of the female gender in their desire to attain or emulate the idealized images of Grecian antiquity, the beauty of Venus, Ceres and Psyche, all blondes according to the Renaissance literature. According to historical sources quoted by Tassini [3], it was indeed the ingenuity of the noble Italian ladies that inspired them to turn from brunettes to blondes. The lightening process, as described by Tassini, required them to spend hours on the balconies of their mansions or palazzos exposing their hair to the midday sun while bathing it from time to time with a tincture of "aqua bionda" or "aqua di gioventu". They covered their shoulders with a silken shawl named Schiavonnette and wearing hats "solanas" that while shading their faces had a circular opening at the top leaving their hair exposed to the sun. Most of the recipes of the aqua bionda contained, apart of water, a mixture of oils, fragrances, leaves of myrtle and wood ash. While none of these ingredients would act as a hair lightener on their own, it appears that the process was an early version of peroxide hair bleaching. Strangely enough, it was the hair pigment that the ladies worked hard to remove that was the essential element and the first step in the chain of events leading to the lightening effect. Photo-bleaching, which is what the ladies practiced, is a two stage process. It involves, through light absorption an excitation of the melanin moiety to a state in which it reacts with oxygen of the air to produce highly reactive superoxide anion $\mathrm{O}^{-}$radical which dismutates in the presence of water to generate hydrogen peroxide [4]. The aqua bionda process had all the elements necessary for success - sunlight, melanin, moisture and even the alkalinity supplied by the wood ash. It is worth pointing out that that the extent of oxidative damage associated with photo-bleaching is relatively trivial. The peroxide is formed in situ, at a relatively low concentration, close to the melanin pigment and with its rate of the melanin oxidation being 20 times faster than that of the disulfide bonds it is being primarily exhausted in the course of bleaching.

Years have passed and it took some years following the synthesis of hydrogen peroxide by Thenard in 1818 before the first commercial hair bleaching product, advertised as "Eau de Jouvence" appeared in France in 1870. Over the years incremental improvements followed and by the time we had an adequate understanding of the process itself, hair bleaching has become a procedure well established not only in beauty salons but also in form of hair lightening kits readily available to the general public.

In view of the apparent simplicity of the bleaching process one should not overlook the fact that melanin pigment exhibits high resistance to acids or alkali and extensive treatments with strong reducing and oxidizing agents cause little change in melanin yet it readily disintegrates in dilute, alkaline solutions of hydrogen peroxide. This relatively rapid dissolution step is followed by somewhat slower process of decolorization. The disruption of melanosomes brings about progressive color changes in hair shifting its color reflectance to warmer tones (Figure 10). 


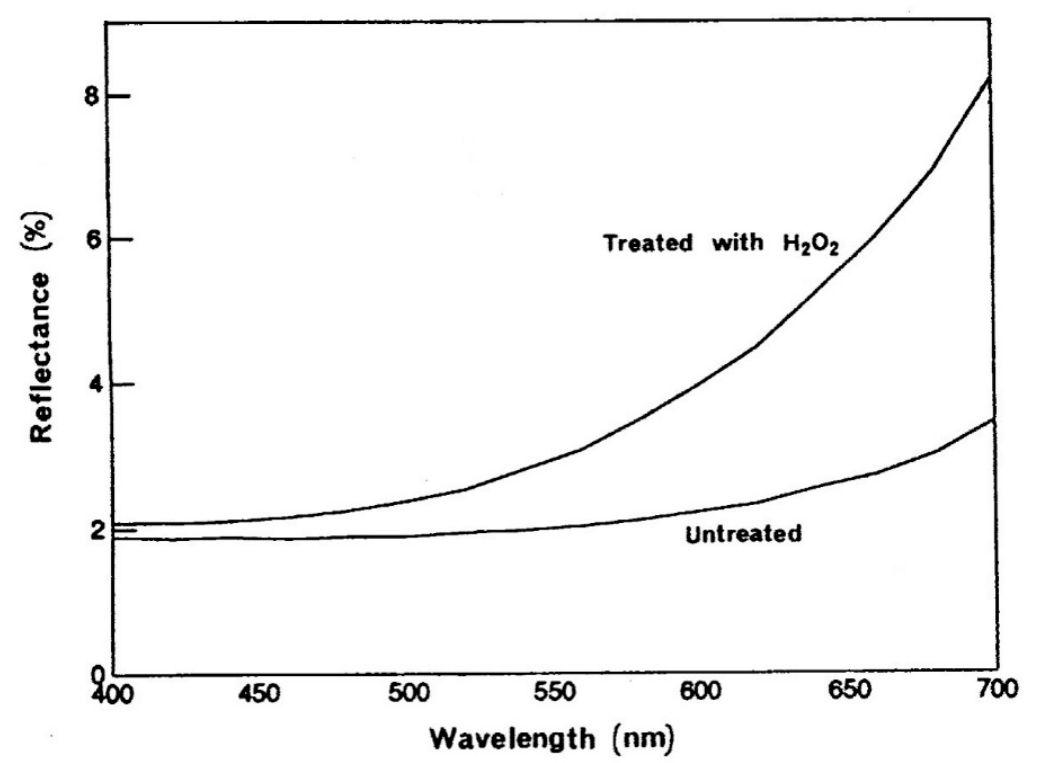

Figure 10. Reflectance spectra of hair, adapted from Wolfram et al. [4], with permission from Society of Cosmetic Chemists, 1987.

In a certain sense, the peroxide alone can be viewed as a colorless hair dye capable of modulating a range of shades of the naturally pigmented hair. This aspect has been utilized in development of permanent hair colorants where peroxide plays a double role-a color modulator and a co-reactant in forming color pigments. The corner stone of the latter was the synthesis in 1883 by Hausmann of para-phenylene diamine. The latter was promptly utilized in combination with phenolic derivatives for dyeing of animal fibers and furs. A French hairdresser was first to offer as early as in 1910 a large palette of hair colors from black to light blond. Unfortunately, the coloring process was multistep, cumbersome and frequently failed to deliver the expected shade. A long period of quiescence followed with new products appearing and disappearing as quickly.

In 1931, an American businessman and chemist, Lawrence Gelb, visited Paris with his wife Clare and on her insistence bought several packages of hair color from a beauty salon, and brought them back to the USA. He set up a laboratory in Brooklyn with a sole purpose to improve and simplify the process and making it highly reliable. Few years later, single step hair color named Miss Clairol was launched at the International Salon Exhibition in New York. Thousands of hairdressers were in attendance and initial disbelief (preparation suites were invaded to check on the process) gave way to a raising welcome. The product was instant success making Clairol the undisputed \#1 hair color manufacturer in the USA. The product accompanied by flashy advertising was distributed to salons only and it was a financial boom to salon owners. A temptation by Clairol to capitalize on the demand led later to widen the distribution of the product via supermarkets and drug stores. The public response was enthusiastic but less so was that of hairdressers who felt betrayed by Clairol turning in large numbers to L'Oreal for coloring supplies.

Thriving public interest in experimenting with hair coloring combined with the ease of application and reliability of performance led to a rapid growth of the market expanding into three general categories. These categories are characterized by the durability of the color imparted to the hair, the type of dye employed and the method of application.

Temporary hair colorants (Figures 11 and 12). These products give relatively poor coverage and are used primarily for highlighting, blending or toning. 


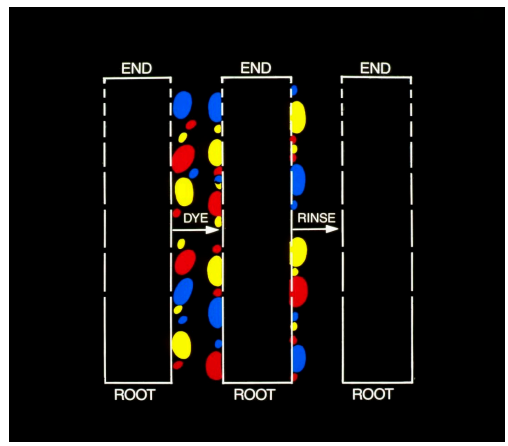

Figure 11. Visualization of interaction of temporary dyes with hair.

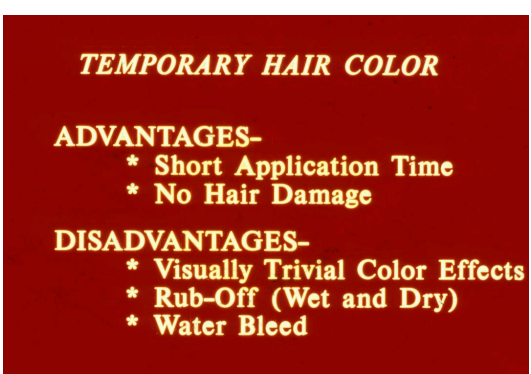

Figure 12. Rudimental elements of temporary hair color.

The most popular commercial products feature leave-in application, wherein the solution is combed through and allowed to dry without rinsing. Water soluble acid dyes are popular in this type of product; some are certified for purity and safety by Federal Drug Administration (FDA), all easily removable in one shampooing.

Semipermanent hair colorants (Figures 13 and 14).

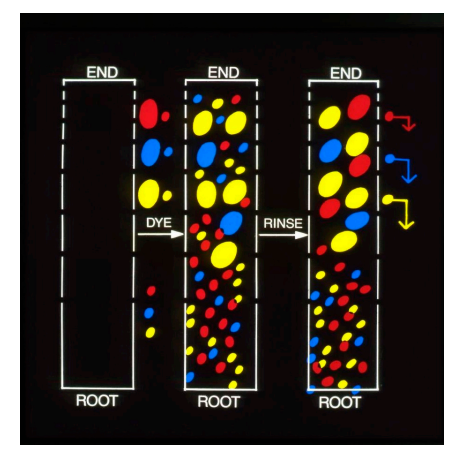

Figure 13. Visualization of interaction of semi-permanent dyes with hair.

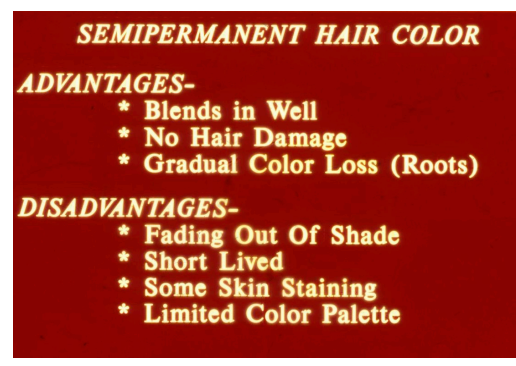

Figure 14. Rudimentary elements of semipermanent hair color. 
The term semipermanent defines hair color product that gives coloration lasting through 5-6 shampoos. This system uses so-called direct dyes that penetrate into the cortex but slowly diffuse out again when the hair is washed. These colorants are often used for gray hair coverage or some modulation of natural hair color without lightening. New entry in this category that requires mixing with peroxide yields longer lasting effects. Permanent hair colorants (Figures 15 and 16).

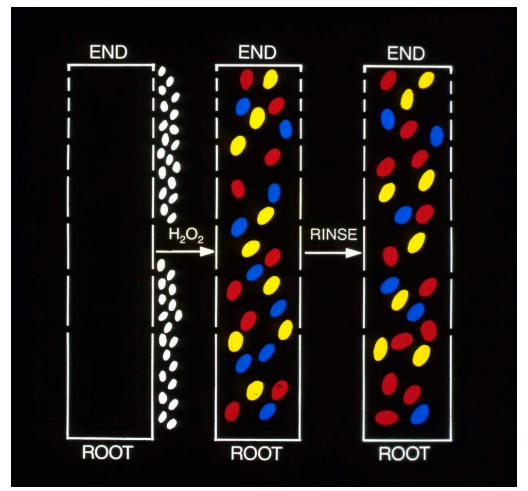

Figure 15. Visualization of interaction of permanent dyes with hair. The dye precursors themselves are colorless.

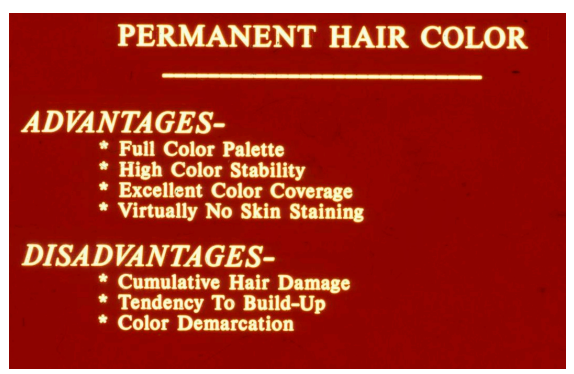

Figure 16. Rudimentary elements of permanent hair color.

Permanent colorants give a result that lasts until the hair grows out. Within this time frame, the shade is resistant towards the action of shampoos, perspiration, sunlight and mechanical abrasion. The most important class in this group is that of the oxidation dyes. In this system, water-insoluble pigments are produced inside the hair fiber by a cascade of steps involving oxidation of colorless intermediates. These colorants can intensify or significantly change the hair color over a wide palette owing to the participation of hydrogen peroxide that not only develops the color but also bleaches the melanin, the natural pigment of hair.

Apart from these three major categories, there are a plethora of hair colorants based on vegetable dyes, pigments, metallic dyes, polymeric dyes, reactive dyes, etc. Interesting as they may be they do not have a major marketing impact.

The medical safety of the hair coloring products has been attested over the years by the very low rate of complaints testifying to effectiveness of the regulatory regulations and requirements such as skin and eye irritation, Lethal Dose (LD) and patch tests. In addition, no one anticipated the furor caused by presentation at the 1975 ACS meeting in New Orleans by Bruce Ames on the mutagenicity of hair dyes. A broad coverage of the presentation by the national press and television helped to foment the apprehension and raise the spectrum of cancer causing almost a panic among the hairdressers. A review of available epidemiological data based on Framingham study of 80,000 female participants suggested negligible risk of cancer incidence among the hair dye users. While number of studies supported this assertion, missing, however, were the hard data on dose penetrations, which were essential in quantifying and validating the risk assessment calculations. Those have become soon available from studies carried out on humans under normal, in-use conditions using $\mathrm{C}^{14}$ labeled 
dyes [5]. The results summarized in Table 1 indicate that the quantity of the absorbed dye is, indeed, a small fraction of that applied to the hair during the coloring process.

Table 1. Uptake of dyes by hair and skin.

\begin{tabular}{cccc}
\hline Dye & $\begin{array}{c}\text { Quantity Applied } \\
(\mathbf{m g})\end{array}$ & $\begin{array}{c}\text { Uptake by Hair } \\
(\mathbf{m g})\end{array}$ & $\begin{array}{c}\text { Percutaneous } \\
\text { Absorption (mg) }\end{array}$ \\
\hline Paraphenylene Diamine (PPD) & 1567 & 360 & 3.13 \\
Resorcinol & 508 & 71.1 & 0.32 \\
2,4-Diaminoanisole (2,4-DAA) & 643 & 143 & 0.15 \\
HC Blue \#1 & 1254 & 75.2 & 1.08 \\
4-Amino-2 Nitro Phenol & 221 & 28.3 & 0.47 \\
\hline
\end{tabular}

Taking these results into account, the risk assessment calculation yielded values $6 \times 10^{-8}$ to $5 \times 10^{-9}$, well below the FDA limit of $10^{-6}$.

An interesting aside of these penetration studies were the data on dye excretion. The results of monitoring urinary recoveries of dyes administered orally or by parenteral injection showed that elimination is rapid yielding $T_{1 / 2}$ values of $4 \mathrm{~h}$ or less. This was clearly not the case for recoveries following hair dyeing where even in the case of hair shaven immediately after the coloring the $T_{1 / 2}$ values varied between 10 and $40 \mathrm{~h}$ suggesting that only trivial amounts of dye penetrated the scalp during the coloring process while the bulk of the urine-recovered dye must have been retained by the stratum corneum and then slowly released into the circulation. Direct experimental support for the hypothesis of the reservoir was obtained by applying a measured quantity of dye to the forearms of human volunteers (thus mimicking the dyeing procedure) and then removing the sequential layers of stratum corneum by stripping with the adhesive tape. Figure 17 illustrates the results obtained with paraphenylene diamine (PPD) and HC Blue \#1, respectively.

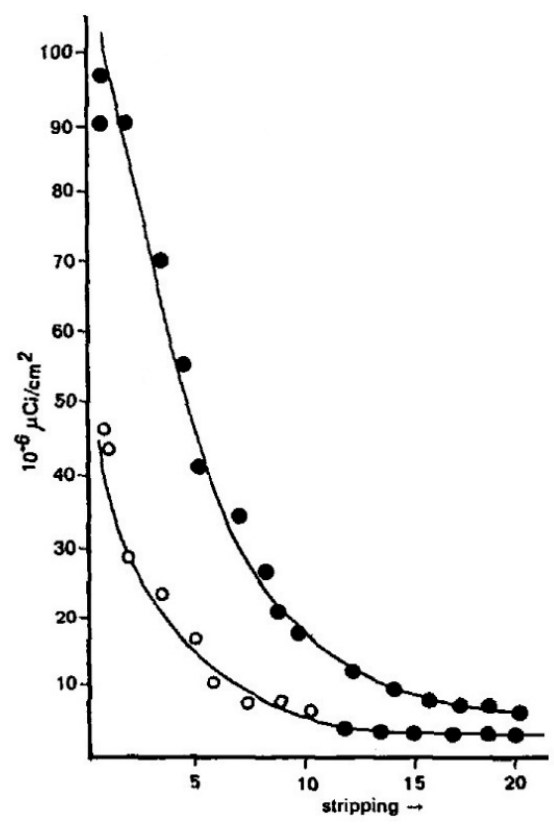

(A)

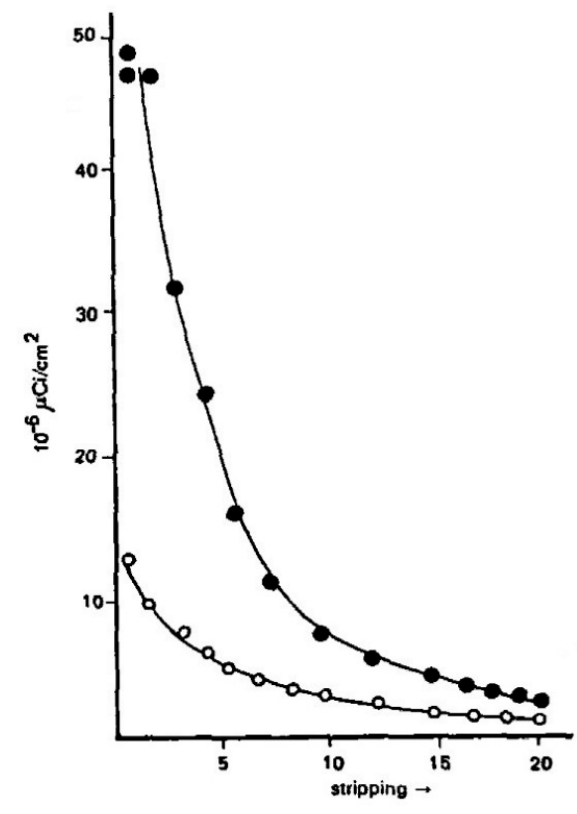

(B)

Figure 17. Distribution of PPD (A) and HC Blue 1 (B) in the horny layer immediately after coloring (solid circles) and $16 \mathrm{~h}$ after coloring (open circles).

The change in the concentration profiles of both dyes is a dramatic demonstration of their mobility in the horny layer and serves as an independent confirmation of the observed kinetics of scalp 
penetration. In view of the comparable mobility of both dyes it is reasonable to assume that the diffusing moiety in case of oxidation dyes is primarily, if not exclusively unchanged PPD. Although the formation of permanent colors involves coupling reactions which are associated with the progressive decrease in the concentration of the oxidative precursors (PPD, diaminoanisole, resorcinol, etc.) it has been shown that as much as $50 \%$ of the originally present precursors is recovered unchanged on completion of the hair coloring. The magnitude of the dye reservoir in the horny layer was readily estimated from the cumulative radioactivity of the isolated strips. A value of $6 \mu \mathrm{g} / \mathrm{cm}^{2}$ was obtained for PPD and a value of $4 \mu \mathrm{g} / \mathrm{cm}^{2}$ was obtained for HC Blue \#1.The standard dye dose used in hair coloring with Nice'n Easy (124) is 1620 mg PPD and with Loving Care it is 1330 mg HC Blue \#1. Assuming the average surface area of the scalp to be $600 \mathrm{~cm}$ the dose absorbed during hair dyeing yields a value of $0.22 \%$ for PPD and $0.18 \%$ for HC Blue \#1. The correspondence between these values and the results obtained from the urinary assays is striking and strongly supports the previously expressed view that the bulk of dye penetration takes place from the horny layer reservoir formed in the course of the hair coloring process.

Whenever the hydrogen peroxide or other oxidants are used with hair, some oxidative cleavage of the disulfide bonds occurs, its severity depending on the nature of the oxidizing agent, its concentration, $\mathrm{pH}$ and length of the treatment. Predominant products of this reaction are the cysteic acid residues. It is important to bear in mind that their formation has an important effect on the molecular interactions within the hair structure. On the one hand, a decrease in the density of cystine crosslinks leads to an overall fiber weakening, on the other hand, generation of cysteic acid residues forces a charge rearrangement phenomenon whereby stronger, virtually acid resistant salt links are formed with the charged amino groups of lysine and arginine.

Having discussed the main efforts in the field of hair coloring, it would be somewhat presumptuous not to mention the nature's achievements in this area. From Scandinavian blondes through Irish redheads to jet black hair of African and Asians, nature astounds us with a rich palette of intense colors and nuances of shades and hues. Yet all of it is accomplished with help of just two, virtually achromatic pigments-eu- and pheo-melanins. A look at their light absorbtion characteristics (Figure 18) indicates a high degree of similarity, clearly one pigment is not black and brown and the other red and yellow.

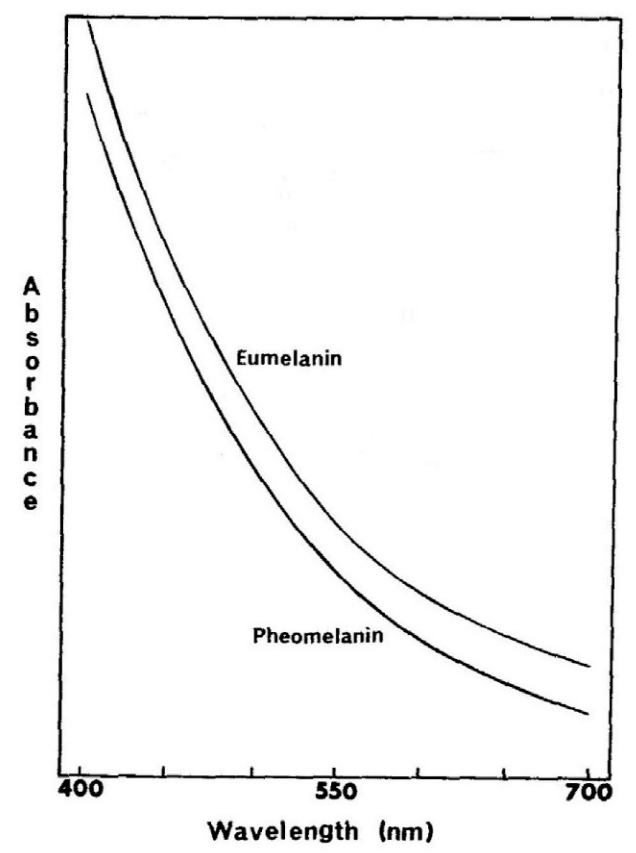

Figure 18. Absorption Spectra of Melanins, adapted from Wolfram et al. [4], with permission from Society of Cosmetic Chemists, 1987. 
The key to this color puzzle lies in the size and the ability of individual melanosomes to absorb and scatter the light $[6,7]$.

In fact, the optical characteristic of melanin mimics that of amorphous semiconductor with the optical density of the former fitting very well into the following expression where $\alpha$ is the optical absorbtion coefficient; $h v$ is the photo energy of incident light; $E_{o}$ is the optical band gap in $\mathrm{eV}$.

$$
(\alpha \mathrm{h} v)^{1 / \mathrm{n}} \sim\left(\mathrm{h} v-\mathrm{E}_{\mathrm{o}}\right)
$$

Figure 19 illustrates the fit.
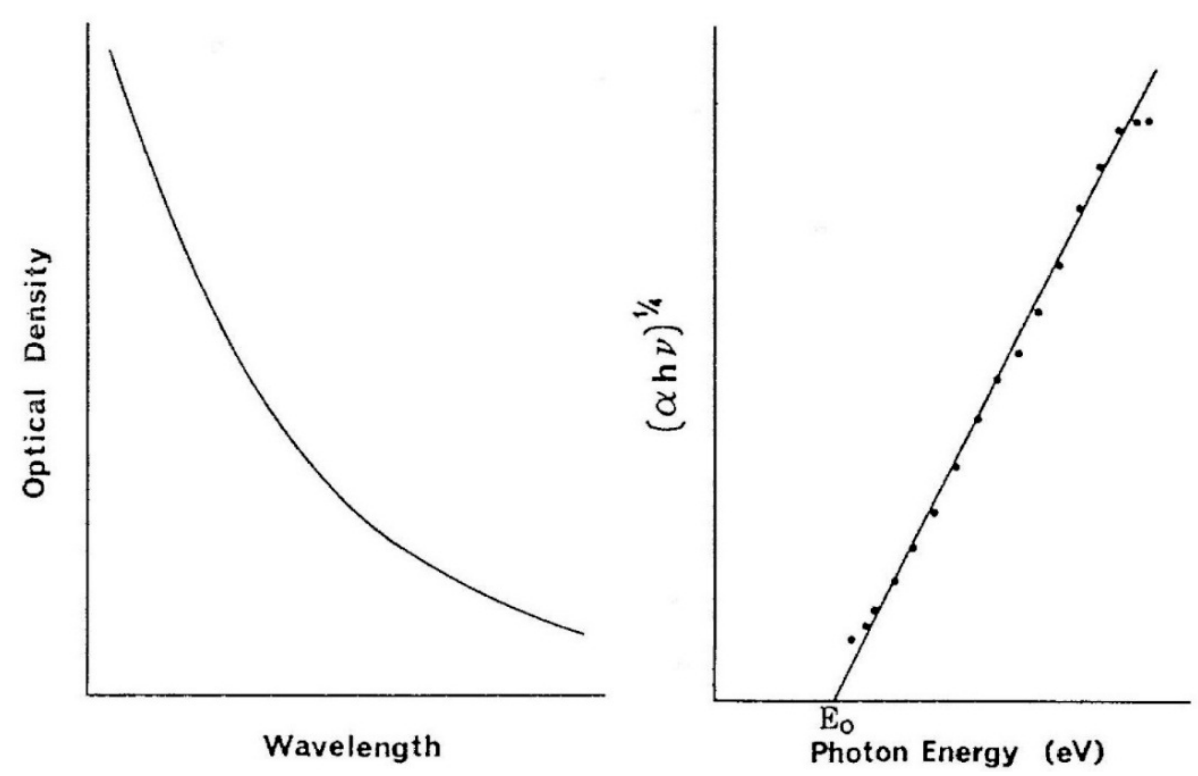

Figure 19. Absorption spectrum of melanin and its mathematical translation.

On the left side is the absorption spectrum of the melanin while on the right its mathematical description as an amorphous semiconductor. The intersection with the $x$-axis defines the value of the optical bandgap. The lower bandgap value the more light-absorbing is the material. Several studies have found that the bandgap of melanin is in the range of $0.9-1.6 \mathrm{eV}$ with eumelanin typically in the range of $1.2 \mathrm{eV}$ and pheomelanin around $1.4 \mathrm{eV}$.

It is important to stress that the absence of chromophic absorbtion bans in melanin does not prevent color display. The latter is a result of the combined effects of multiple Mie scattering and absorbtion processes. The intensity of this diffusively reflected light varies with wavelength giving the color we perceive when signals it produces in our eye are processed by the brain. In the reference to the importance of the scattering/absorption phenomenon, Figure 10 reflects the modulation of melanosomes in black hair by peroxide and its effect on the reflectance characteristic. Similarity of the effects between the hair and pure melanin is remarkable (Figure 20).

While the amorphous semiconductor approach to the interpretation of hair color appears quite reasonable, clearly the soundness of such interpretation needs to be tested in predictive terms. A hypothetical model was developed [8] using the following assumptions: 


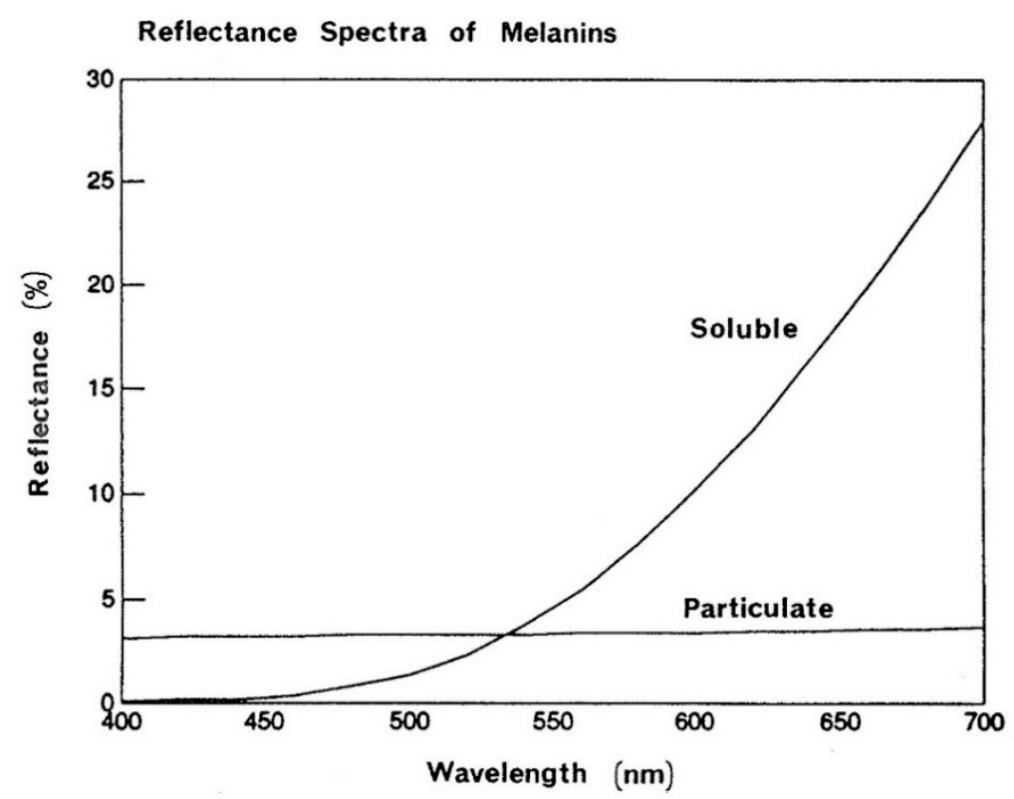

Figure 20. Reflectance Spectra of Melanins, adapted from Wolfram et al. [4], with permission from Society of Cosmetic Chemists, 1987.

\section{Both the Absorption and Scattering Contributes to the Color of Hair}

(a) The bandgap values between 1.1 and $1.2 \mathrm{eV}$ for eumelanin and between 1.3 and $1.4 \mathrm{eV}$ for pheomelanin.

(b) The distribution of the melanosomes in hair is random with the sizes varying between $0.2 \mathrm{~m}$ and $1.0 \mathrm{~m}$ and the size is spherical.

(c) White hair is the base for optical characteristic of the hair matrix.

(d) Apart from medulla there are no voids in the hair.

The data presented in Table 2 compares the measurements carried on hair tresses with the calculated color parameters $L, a$ and $b$ and the dominant wavelength.

Table 2. Color Parameters of Hair.

\begin{tabular}{ccccc}
\hline & $\boldsymbol{L}$ & $\boldsymbol{a}$ & $\boldsymbol{b}$ & Dominant Wavelength (nm) \\
\hline Exp. & 14.6 & 0.4 & 1.1 & 583 \\
Model & 13.9 & 0.5 & 0.8 & 586 \\
Exp. & 16.6 & 0.2 & 2.0 & 579 \\
Model & 18.6 & 0.7 & 1.8 & 583 \\
Exp. & 18.4 & 1.8 & 3.3 & 584 \\
Model & 19.4 & 1.3 & 3.6 & 584 \\
Exp. & 23.4 & 5.8 & 9.0 & 586 \\
Model & 22.0 & 4.9 & 8.7 & 586 \\
Exp. & 30.3 & 7.5 & 12.0 & 586 \\
Model & 33.5 & 5.6 & 12.3 & 583 \\
Exp. & 43.5 & 3.9 & 15.5 & 581 \\
Model & 46.3 & 4.2 & 15.1 & 582 \\
\hline
\end{tabular}

They suggest a reasonably good correlation for both the color intensity and respective chromatic character. It would be interesting to see if the work in this area will continue. As a brief aside on this subject it is worth mentioning that an experimental works, and indeed with some commercial overtones, has been carried out on trying to mimic nature by depositing the melanin pigment in the 
hair. I allude here only to one example of such effort, Figures 21 and 22 illustrating the approach and result.

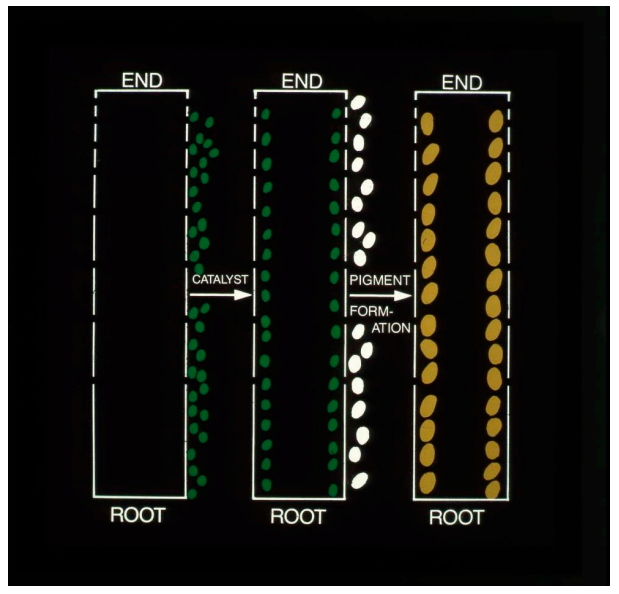

Figure 21. Coloring of hair with melanin precursor.

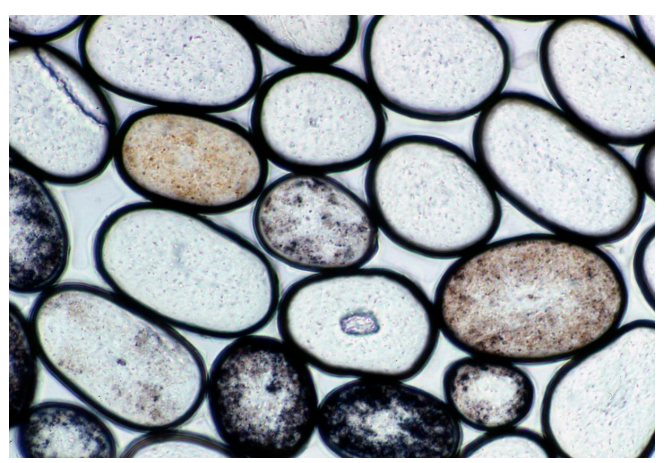

Figure 22. Cross-sections of hair dyed with melanin precursor.

\section{Looking Deeper into the Hair}

It is worth bearing in mind that well into the 20th century the knowledge of keratin structure, its composition and the reactivity has been meager at best. While the textile processing of wool including dyeing and steam setting was relatively well developed, the know-how focused primarily on "how" and relied significantly on experiences gained over the past years. It almost seemed as if once the successful processing and effective dyeing procedure were established there little apparent quest for more fundamental knowledge of the fiber itself. A similar situation existed in the hair care industry where there was little innovation challenging the established hair setting and coloring techniques while the attempts to permanently modify the shape of the hair were primarily based on trial and error approaches.

It was the landmark publication of Hermann Staudinger in 1920 [9] postulating that rubber and natural fibers such as cotton or wool are polymers, composed of long chains of repeated units linked by covalent bonds that opened completely new era of research. Staudinger's views met initially with disdain and skepticism even by famous chemists such as Emil Fisher and Wieland who believed that the high molecular weights found for these materials are only apparent, caused by aggregation of smaller units into colloids. It was not until X-ray diffraction studies by Hermann Mark's on cellulose [10] and Astbury's on wool [11] that the matter has been settled initiating highly promising approach to structural investigations. Coincidental breakthrough in the techniques of amino-acid analysis significantly aided investigations into the chemical composition of proteins thus broadening the scope of studies. Financial support from the wool industry was instrumental in helping the University 
of Leeds England to become a center of wide ranging explorations into the wool structure and its chemical properties. While Astbury and Woods [12] focused on keratin structure (discovery of $\alpha$ to $\beta$ transformation) the chemistry of keratin fibers, both wool and hair was the domain of Speakman [13].

He soon realized that the focal point of chemical reactivity of keratin is the disulfide bond of cysteine, which can be readily oxidized, reduced and hydrolyzed yielding a variety of reaction products, but also fundamentally impacts the properties of the fiber. The breadth of his investigations and his focus on the potential practical utility of cystine crosslinks led a reverend description of his laboratory as the Cystine Chapel. Speakman's studies have invigorated research on keratin in the USA [14] and Germany [15] leading to a flurry of original publications and patents. His findings that the reductive cleavage of cystine crosslinks are reversible and can be exploited to impart a stable change of the fiber configuration led him to patent in 1936 the first prototype of the "cold" permanent wave. The apparent ease of application combined with the relatively low cost of ingredients established the cold waving process as an immediate marketing success. As was the case with hair coloring, the hairdressers were the main beneficiaries of this invention as the hair manipulation associated with the process is cumbersome and, depending on size of rollers used, may be difficult to perform by unskilled consumers.

In contrast, however, to hair coloring, where the hair serves primarily as a receptacle of coloring moieties, the hair waving process is highly complex engaging selectively the histological and structural components of the fiber and, depending on $\mathrm{pH}$, responding differently to the employed reagents. In essence, the immediate objective of waving is to impart to hair a durable configuration that is different from the one hair exhibits in its native form. The latter is the result of processes of keratinization and follicular extrusion that transform a viscous mixture of proteins into strong, resilient and rigid keratin fiber. In principle, waving can be viewed as a combination of reversal and stepwise restaging of these processes, as it entails softening of keratin, molding it to the desired shape and annealing the newly imparted shape. The underlying mechanism of waving is thus essentially molecular involving manipulation of physico-chemical interaction that stabilize the keratin structure.

It might be useful at this point to emphasize the essential difference between waving and setting of hair. Although in both cases we deal with impartation of new geometry to hair, only water labile bonds are manipulated in setting and thus the new configuration is moisture sensitive and is lost on shampooing. In waving, both the secondary and covalent bonds are involved and the newly imparted geometry is stable to repeated washing cycles. The cleavage of the disulfide cross links is as essential for the softening of the fiber as their reformation is to the stability of its new configuration. Needless to say, the secondary interactions such as hydrogen bonds, salt links, and hydrophobic bonds participate therein and their more or less intense contributions reflect themselves in the overall efficacy of the process. Nevertheless, so far, it is the disulfide bonds, which are the corner stone of the permanency of the process. Over the years, there have been numerous attempts to explore the ways of permanently altering the geometry of keratin fibers by exclusive manipulation of secondary bonds. Some success has been demonstrated in fibers modified by inclusion of bulky apolar residues or by high temperature steam setting (crimping of wool and commercial hair) but except for steam setting such approaches found little, if any, application either because of the complexity and severity of treatment conditions or because of unsatisfactory results.

In the course of waving, the hair fiber is subjected to both chemical and physical stimuli. The chemical processes of disulfide bond cleavage/reformation and secondary bonds re-arrangements are accompanied by swelling and physical stresses of extension and compression as the hair is wound on the rollers. Due to different chemical and physical make-up of the histological components of the fiber, they are likely to respond in a different manner to these stimuli. An increased elucidation of function and properties of hair histological and structural elements while not directly resulting in radical improvements of the waving process has provided a better insight into the performance parameters. Thus, for example, it has been known that hair diameter has significant effect on hair wave ability and the durability of imparted curls. While the physics alone can adequately account for the faster curl decay in fine hair, the fact that the curl impartation itself is also negatively impacted in 
such hair was not obvious. It appears that explanation [16] can be related to the fact that the cuticle layer in hair is diameter invariant and thus its weight fraction in fine hair can reach a value as high $25 \%$ impairing the waving ability of hair which is primarily determined by the fibril/matrix composite not present within the cuticle structure (Figures 23-25).

Very low wet torsional modulus of the cuticle, which is, at most, 1/10 of that of the cortex impacts negatively the stability of newly imparted configuration. While a negative asset in waving the readily accessible cuticle offers potentially rewarding depository of materials that could mechanically strengthen the fiber or lead to a better set (hydrophobic materials acting by reducing the water content of the cuticle).

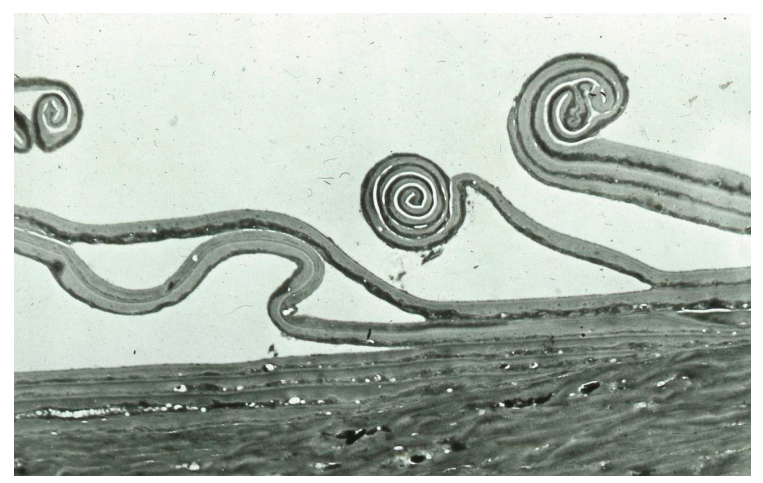

Figure 23. Hair cuticles in hair that has been pulled from the scalp.

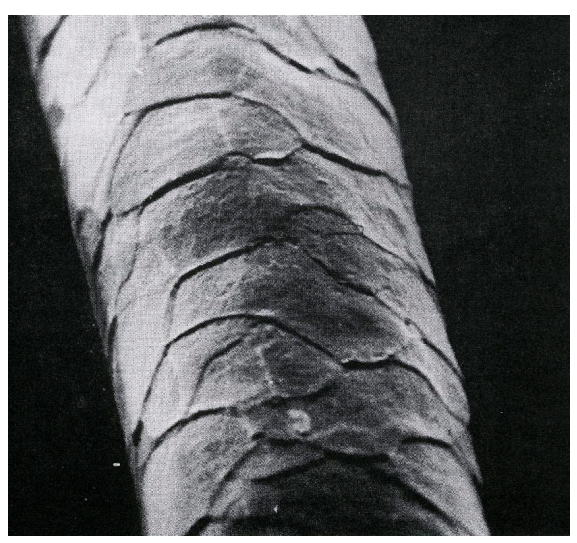

Figure 24. Scanning electron micrograph of intact mohair.

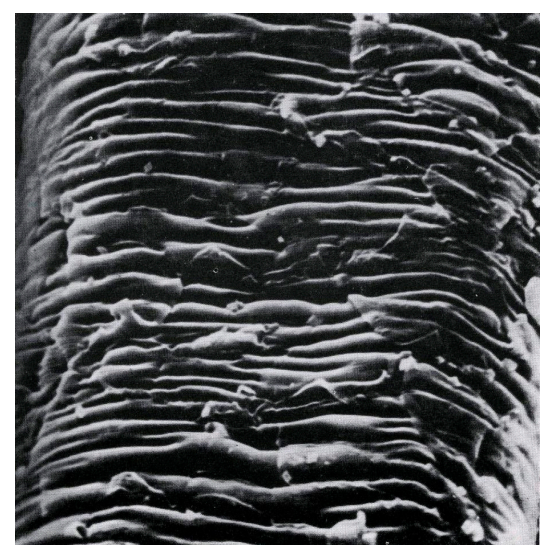

Figure 25. Scanning electron micrograph of supercontracted mohair. 
Turning to the cortex, which is the weight dominant component of the fiber, one is quite comfortable in assigning it as the principal actor in waving. Yet, we are confronted here with the enigma of its ultrastructure. It is generally agreed that the structure of the cortical cell is of biphasic nature, consisting of axis-oriented filaments embedded in non-filamentous matrix. Combined evidence of electron microscopic examination and protein analysis led to a postulate that the filaments are made up of highly organized, cystine-poor helical proteins while matrix consists of proteins chains heavily cross-linked by disulfide bonds. This postulate combined with the physical measurements suggests that the mechanical properties of matrix and filaments (fibrils) are similar in the dry fiber but in the wet hair the matrix is the soft phase while the filaments are the weight bearing units.

The apparent contradiction between the dense cross-linking of matrix and its high swellability in water has been explained [17] by postulating that high cystine content of matrix interferes with the tendency for highly organized arrangements of proteins making them more water accessible than the helical fibrillar components. Recently there has been reassessment of these views with less emphasis on the rigid compartmentalization of protein components.

Location of the high sulfur proteins within the matrix predestines it as the primary sites of reactions occurring during waving. One can readily envisage that the reduction step leads to further softening (plasticization) of the readily accessible matrix allowing for high degree of its deformation under waving stress and stabilization of its new structure by reformation of disulfide bonds reinforced by secondary bond re-arrangement. However, if the cystine-deficient filaments, which are thought to be mainly responsible for mechanical integrity of hair under wet conditions, did not participate in the waving process what would prevent the fiber snapping back to its original configuration? Both Wortmann and Feughelman [18,19] address this issue focusing on major differences in efficacy between the fibers set in bending configuration as against extension. They both focus on changes in bending moment that provides either the stability of the new configuration or recovery to the original state.

While a number of nucleophiles are known to be effective in cleaving the disulfide bond of cystine only three found the practical use-mercaptans, sulfites and hydroxide. Let's briefly explore some fundamental aspects of the reaction involved with each of these in terms of their efficacy and limitations.

The course of most reactions in a homogeneous system can be fully characterized by three process parameters-rate constant, equilibrium constant and energy of activation. From these the rate constant is descriptive of the kinetics of the process while the equilibrium constant, being a thermodynamical quantity, informs us of the nature of the reaction and its final outcome. The situation is somewhat more complicated in a non-homogeneous system, where, in addition to the parameters cited above the diffusion of the reagent(s) to the reaction sites has also to be considered. The latter clearly affects only the kinetics of the process and has no bearing on the equilibrium constant.

The reduction of hair that takes place during waving is carried out under "kinetic" conditions with the fiber accessibility governing the diffusion pathways. The equilibrium constant of the reduction remains, however, the more fundamental quantity providing essential information on the nature of the reaction. A particularly attractive aspect of the equilibrium approach is that it provides us with information regarding the extent of keratin reduction, which is of essential practical importance.

\section{Disulfide Bond Cleavage by Mercaptans}

The reagent most frequently for the reduction of hair is thioglycolic acid (TGA). Although a great variety of other mercaptans have been screened, none of them has been able to match the unique combination of efficiency, safety and low cost that the hall mark of TGA.

It is generally accepted that the reaction of mercaptans (RSH) with the combined cystine in hair (KSSK) proceeds [20] via a sequence of two reversible nucleophilic displacements (Figure 26). 


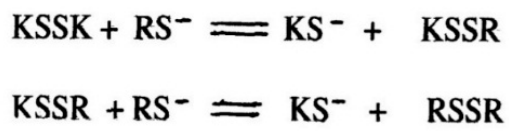

Thus, overall

$\mathrm{KSSK}+2 \mathrm{RS}=2 \mathrm{KS}^{-}+\mathrm{RSSR}$

$$
\mathrm{K}=\frac{\left[\mathrm{KS}^{-}\right]^{2}[\mathrm{RSSR}]}{\left[\mathrm{RS}^{-}\right\rceil^{2}[\mathrm{KSSK}]}
$$

Figure 26. Scheme of the reaction between hair and mercaptans.

A commonplace assumption is that to attain the maximum cleavage it is necessary to use either a large excess of thiol or run the reaction under strongly alkaline conditions that seem indispensable for the generation of the attacking nucleophile-mercaptide ion. The nature of the things is, however, somewhat more complex. Examination of the equilibrium constant $\mathrm{K}$ of the overall reaction reveals that while excess of mercaptan will always force the reduction, an increase in $\mathrm{pH}$ would not, by itself, assure of similar trend. This is because the equilibrium level of cleavage $\alpha$ is controlled by the ratio of ionized keratin thiol to that of the attacking mercaptan. Figure 27 illustrates the expected $\mathrm{pH}$ dependence of cleavage $\alpha$ by hypothetical mercaptans with $\mathrm{pK}$ values lower, equal or higher than that of keratin sulfhydryl. This relationship has been tested and confirmed for number of mercaptans and found its application in so called "acid waving".

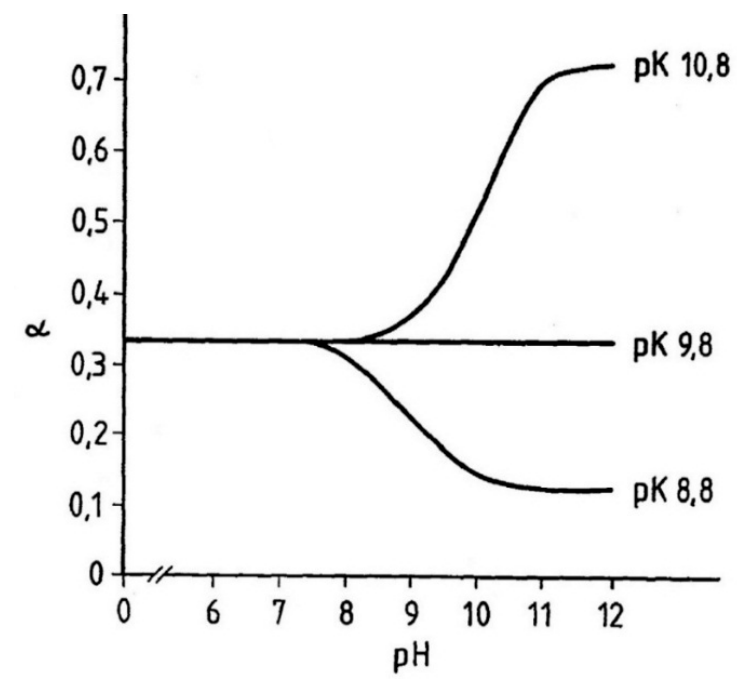

Figure 27. Reaction of hair with mercaptans of different pK values, adapted from Wolfram et al. [20], with permission from SAGE Publications, 1966.

In most of the current waving formulations the concentration of TGA ranges from 0.6 to $1.2 \mathrm{M}$ and with the lotion to hair ratio 1-1.5 there is sufficient supply of reductant to reduce most of the disulfide bonds in hair. Yet, the extent of disulfide bond cleavage $\alpha$ is seldom higher at full penetration of the fiber than 0.3-0.4 which is to be expected from the equilibrium-pH profile of the reaction. It is important to emphasize this as it bears directly on the issue of waving efficacy. An interesting example of a mercaptan that transcends the conventional equilibrium approach is 1,4-dithiothreitol (DTT). 
The keratin-DTT moiety formed in the first step of the reaction undergoes rapid autocleavage to yield sterically favorable cyclic disulfide generating in the process a second cysteine residue. It is interesting that neither DTT nor tertiary phosphines are good waving agents in spite of being excellent disulfide bond reductants. As in the case of TGA, the reduction of hair is diffusion controlled, yet at cleavage levels of $0.3-0.4$ they are very poor performers. The explanation of their failures lies, paradoxically, in the fact that they are too good reductants; their reduction equilibrium are shifted totally to the product side. As their diffusion front moves through the fiber, most, if not all of the disulfide bonds left in their wake are reduced. This means, assuming uniform distribution of the combined cystine that only $30 \%$ of the fiber volume has been penetrated, compared with $100 \%$ penetration by TGA. This, of course, implies that $70 \%$ of the fiber has remained in its intact, unreduced state and can substantially recover the native conformation on the completion of the process.

\section{Disulfide Bond Cleavage by Sulfite}

The reaction between combined cystine in hair and sulfite proceeds according to the scheme: shown in Figure 28.

\section{$\mathrm{KSSK}+\mathrm{SO}_{3}=\mathrm{KSSO}_{3}^{-}+\mathrm{KS}^{-}$}

Figure 28. Reaction between hair and sulfite.

The reaction consists of one step and no exogenous products are formed. Unlike TGA, which generates two cysteine residues per disulfide bond cleaved, sulfite yields only one and a Bunte salt side chain. Using the above equation and the values of respective ionization constants the theoretical extent of reaction $\alpha$ was computed as a function of $\mathrm{pH}$. The computed values (solid line) are compared to experimentally determined value in Figure 29.

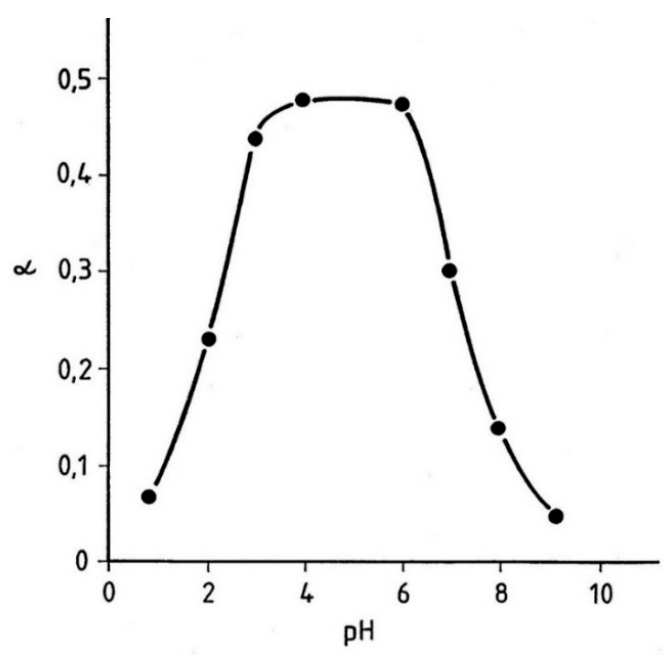

Figure 29. Effect of $\mathrm{pH}$ on the reaction of hair with sulfite, adapted from Wolfram et al. [20], with permission from SAGE Publications, 1966.

The close fit is quite remarkable particularly in view of the complexity of the system. Although the $\mathrm{pH}$ profile of the equilibrium is self explanatory, some comments regarding the nature of the reaction may be useful. The plateau of the maximum cleavage level that occurs between $\mathrm{pH} 3$ and 6 slopes steeply on both sides of this range. The drop in cleavage between $\mathrm{pH} 3$ and $\mathrm{O}$ is due principally to the precipitous fall in the sulfite nucleophile concentration in this range while the decrease in $\alpha$ above pH 6 is caused by shift of the equilibrium-reaction reversal—caused by increased ionization of the combined cysteine side chains. This, in turn, implies that even by exposing the hair to conditions of 
maximum cleavage level (say, $\mathrm{pH}$ 6) a substantial disulfide bond reformation can take place in the fiber by simply raising the $\mathrm{pH}$ of the reaction medium. As in the case of TGA the rate of hair reduction is diffusion controlled. However, because of the different reaction mechanism the $\mathrm{pH}$ role in the process is substantially modified. In general, an increase in the alkalinity of the medium promotes swelling of hair by ionization of the keratin sulfhydryls and weakening of the secondary interaction. In the case of sulfite, due to the low disulfide cleavage level under such conditions, the effect is trivial and of little assistance to the diffusion process. Indeed, the negative charge on the fiber appears to shield the hair from the entry of the negatively charged nucleophiles and the time for complete hair penetration may be as long as $60 \mathrm{~min}$. At the neutral $\mathrm{pH}$ range the penetration time is much shorter $(20-30 \mathrm{~min})$ and the disulfide bond cleavage is extensive but it is not accompanied by a corresponding rise in swelling. The reason for this lies in the fact that under such conditions the ionization of the keratin sulfhydryls is minimal and the coulombic interactions (salt links) remain undisturbed. Thus, although the extent of reduction approximates that of TGA, the degree of fiber softening is much less negatively affecting its moldability.

Nevertheless, several sulfite-based waving formulations have been developed and, exploiting lack of unpleasant odor when compared to TGA products, successfully marketed (Rave and Kindness). A more aggressive formulation containing urea has been marketed for straightening of Afro hair (Curl Free). An interesting illustration of the difference in the mechanism between mercaptans and sulfite is shown in Figure 30 depicting the waving efficacy treated hair after rinsing but without peroxide neutralization.

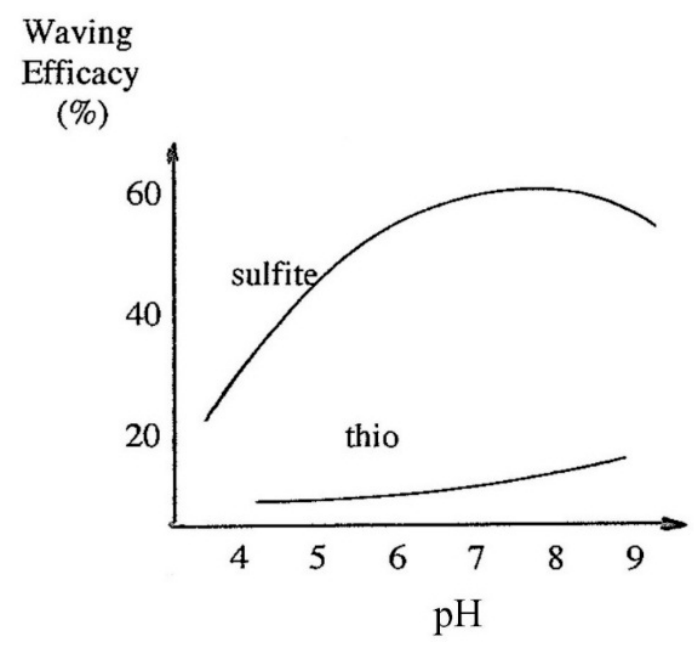

Figure 30. Waving efficacy of hair without peroxide neutralization [21].

\section{Reaction of Hair with Alkali}

All proteins are susceptible to degradation by alkali, due to hydrolysis of peptide bonds and amide side chains, yet through ingenious formulation efforts medically safe products have been developed for the sole use as straighteners (relaxers) of African type hair. They are usually in form of viscous lotions or creams and contain, as an active ingredient, sodium hydroxide or combination of guanidine and sodium carbonate. The effective $\mathrm{pH}$ at use is $12-13$. The efficacy of such products accompanied by spontaneous straightening is noticeably superior to formulations based on TGA or ammonium sulfite although it is associated with more pronounced hair damage. As to be expected, the cystine cross links are heavily involved in the reaction but the cleavage takes place at the carbon adjacent to the disulfide bond (Figure 31). 


\section{Alkaline Degradation of Cystine}

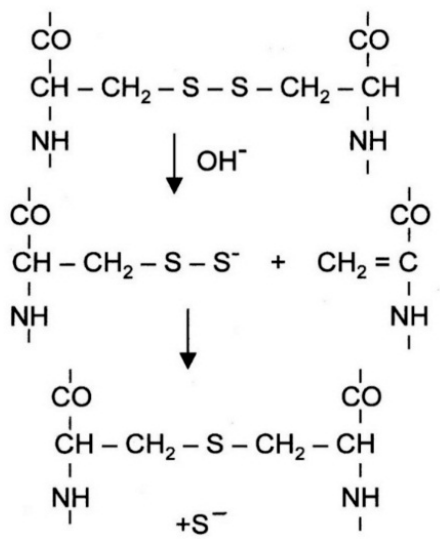

Figure 31. Alkaline degradation of Cystine [22].

This is rapidly followed by formation of a new cross links of lanthionine together with some lysinoalanine and concurrent ejection of the sulfur atom in form of $S^{=}$. The latter is one of the strongest nucleophiles known and can readily cleave the still available cystine crosslinks further swelling the fiber and weakening the native geometry. It turns out that the freshly formed lanthionine (and lysinoalanine) cross links add little if anything to the retention of new (straight) conformation. The latter appears to result from an extensive and irreversible modification of the filament/matrix composite [23,24].

\section{Hair-Water Interaction}

To put in proper perspective the nature of this interaction, it is important to keep in mind that the biosynthesis of hair occurs in an aqueous environment and that the final keratinized structure is in mechanical equilibrium while in a wet state. As the swollen fiber dries on emerging from the follicle, the equilibrium memory is retained and then restored on wetting. This hydration-dehydration process is highly anisotropic being accompanied by a 15\% diametric swelling with only $1 \%$ change in length. This phenomenon is well accounted for by the two-phase composite model of the keratin structure in which the radial expansion and contraction of the hydrophilic matrix in the hydration-dehydration cycle brings about only a small change in the axially oriented microfibrils.

Keratin's high affinity for water extends over the whole range of relative humidity and, although water permeates hair readily, there is binding selectivity within the molecular structure as well as accessibility restraints in the filament and matrix texture. Available data on moisture binding by hair of different ethnic origin reveal no significant differences in uptake although some controversy exists as to the precise values of absorbed water.

Reactive cosmetic treatment of hair (waving, relaxing, bleaching and coloring) while resulting in some disruption of the fiber structure have, on the whole, marginal effect on water absorption at ambient humidities but cause significant increase in hair swelling while wet (Table 3).

Table 3. Effect of hair treatment on moisture uptake by hair [25].

\begin{tabular}{cccc}
\hline \multirow{2}{*}{ Treatment } & \multicolumn{3}{c}{ Moisture Regain (\%) at } \\
\cline { 2 - 4 } & $\mathbf{6 5 \%} \mathbf{R H}$ & $\mathbf{9 5 \%} \mathbf{R H}$ & Liquid \\
\hline Intact & 15 & 32 & 34 \\
Dyed & 15 & 32 & 36 \\
Bleached & 16 & 35 & 50 \\
Waved & 15 & 33 & 41 \\
Relaxed & 15 & 34 & 57 \\
\hline
\end{tabular}


As the moisture sorption is a key element in the stability of styled (set) hair there have been numerous attempts over the years to lower the moisture uptake by variety of means. One of the earliest were those of Speakman [26] who exploited keratin's affinity for acids to decrease the water binding. The magnitude and durability of the effect is dependent on the size of the associated anion. A significant improvement in hair settability can be attained, although the effect slowly disappears on repeated shampooing as the acid moieties desorb from the hair. It is worth noting that this "acid" approach to moisture modulation has been in recent years exploited for styling of African hair.

Extensive studies carried out on the reactivity and attendant structural changes of proteins in aqueous environment revealed that the accessibility of the reactive sites and the hydrogen-bonded conformation of the macromolecules are greatly affected by solutes like urea and higher molecular weight alcohols. While the latter are clearly less effective hydrogen bond breakers than water itself their presence in aqueous solution appears to potentiate the water activity. Thermodynamic calculations carried out by Klotz and Nemethy $[27,28]$ showed that this was due to the disruption of "water icebergs" or hydrophobic interactions resulting from co-operative effects between water and the apolar side chains. Thus, a unique property of the hydrophobic bond is its existential dependence on presence of water.

A question arose whether such a hydrophobic interaction could be utilized for hair modification as a potential route to moldable hair and thus possibly to develop system where water stable configuration could be changed repeatedly by manipulation of the secondary bonds alone. This approach was tested by incorporation of apolar groups into hair. A two-step process was designed [29] where reduction of disulfide bonds in hair was followed by the step of their alkylation with $N$-alkyl maleimides. The alkylation of reduced hair significantly lowers its water absorption and its swelling in water while remaining swollen and pliable while in aqueous solutions of alcohols. An attempt was made to exploit this change in the swelling characteristics for styling. Thus, the hair tresses swollen in $50 \%$ aqueous propanol were set on rollers, rinsed with water and air-dried. They were then removed and evaluated, hanging freely in a chamber at $85 \%$ RH. The data show that even at prolonged exposure to high humidity the alkylated hair retains its imparted curl. On immersion in the aqueous alcohol the tresses regained their native configuration and could be then repeatedly set and released with no change in their styling performance. The main drawback of the system was negative impact of the treatment on the strength of wet hair. At $40 \%$ reduction level necessary to introduce into hair sufficient number of alkyl groups needed for durable styling characteristics, the fiber was permanently weakened with just over $20 \%$ loss of strength. While the hydrophobic bonds compensated somewhat for the $40 \%$ strength loss associated with the reduction step. The low bonding energy ( $5 \mathrm{kcal} / \mathrm{mol}$ ) of such bond could not match the energy loss of $50 \mathrm{kcal} / \mathrm{mol}$ of a broken cystine cross link.

\section{Hair Conditioning}

It is not surprising that during its long residence on the scalp the hair undergoes changes in appearance and properties. Exposure to sunlight combined with a rudimentary hair care regimen such as washing, combing, brushing and styling leads to some loss of shine and smoothness negatively affecting its feel and ease of combing. In the past, these progressive changes in hair properties have been tacitly accepted as a natural turn of things and unhurriedly dealt with by the use of kerchiefs to protect the hair from sun and mixtures of vegetable extracts and oils to maintain (or restore) the hair luster while keeping it soft and easy to comb. Introduction of chemical processes such as hair coloring and waving has radically changed all that. A great satisfaction with a new shade or enticing curl was unexpectedly confronted with sudden shock of highly undesirable changes in hair tactile properties, leaving it rough to touch and almost uncombable. That what in the past has taken months to notice now only took one hour or so. An ominous and sinister word has appeared in the hair care vocabulary-hair damage. It has become clear that something substantially different from the then available palliatives was needed, particularly as the demands in the overall area of hair esthetics have remained unmet. Growing understanding of the chemical nature of changes brought about in hair by the chemical treatments combined with the relevant technology in the textile wool industry 
led to introduction of cationic surfactants in the hair care with The Toni Company of Chicago as the first to use the steralkonium chloride initially in the final "rinse" in their waving kits and then as a freestanding conditioning product "Tame". To the consumers the product seemed nothing short of miracle. A minute rinse and the hair became lustrous, silky soft, easy to comb and free of "static". Among the hair products then available Tame was doubtlessly the best value for money with one small drawback - it had to be applied after each shampoo. That transitory effect had not been addressed until cationic polymers and silicones came into the play but even now the effective durability of conditioners remain matter of dispute and belief.

There is little doubt that both the oxidative and reductive processing of hair can be associated with undesirable changes in hair that are readily perceived by the consumers and viewed as damage. The changes most obvious are those associated with modification of hair surface. In most cases, this is adequately dealt with by application of conditioners whether by rinse or leave-on products. Clearly a durable surface grafting of appropriate materials (preferably polymers) would go a long way not only to mask but to genuinely repair the damage. As of now, no reliable and medically safe systems are available to deliver such coating. The same goes for internal polymer grafting. In the latter case significant modulation of the water sorption characteristic of hair can be attained with a genuine increase in fiber strength and/or improvement of hair setting properties. However, most of the monomers that meet the desired effects do not meet the safety requirements. An interesting exception is a condensation polymerization system employing resorcinol and glyceryl aldehyde. The reaction can be successfully carried out in an aqueous system at ambient temperatures attaining within hour or so internal polymer deposits at a level that both strengthens the fiber and imparts to it some heat moldability.

For most reactive commercial products, when used according to instruction, the modification of hair cortex, while readily discernible by fiber testing is not a cause of genuine worry for consumers. Nevertheless in the competitive world of cornucopia of products one finds oneself frequently surrounded by psychosis of damage epidemic with the creativity of claims bordering often on creationism where the substantiation facts of the former match ridiculous assertions of the latter.

I have attempted to provide you with a concise overview of progress that has taken place over the years in understanding the chemical properties of hair and their relation to the development of hair care processes. It is, however, important to realize that in spite of time-impressive chronology, our current understanding of structure and chemical reactivity of hair has been attained within last 60 years and so. Some of us have not only been witnesses of this built-up of knowledge but have made significant contribution to it. The 1950s and 1960s years have in fact been a golden age in the field of keratin research. The latter thrived not only in the academic institutions at Leeds, Aachen, Albany, Textile Research Institute at Princeton and CSIRO in Melbourne and Sydney but also in number of industrial laboratories such as L'Oreal, P \& G, Unilever, Gillette, Clairol, Colgate, Wella and Henkel.

\section{Conclusions}

By the end of the 20th century, the basic tenets of hair structure and its physicochemical properties were well established. In consequence, a range of efficacious processes and products have been developed that met with overall consumer satisfaction. It is yet not clear what is the path for future progress in this field. Perhaps, the explosive development of nanotechnology could be utilized either to improve the efficacy and esthetics of current products or lead to novel approaches. The same goes for potential practical utilization of lasers, both for photobleaching of hair or its styling.

Conflicts of Interest: The author declares no conflict of interest. 


\section{References}

1. Wade, N. East Asian Physical Traits Linked to 35,000 year old mutation. Available online: http://www. amren.com/news/2013/02/east-asian-physical-traits-linked-to-35000-year-old-mutation/ (accessed on 13 February 2013).

2. Elberg, H.; Troelsen, J.; Nielsen, A.; Mengel-Fral, J.; Kiaer, K.M.; Hansen, L. Blue eye color in humans may be caused by a perfect association founder mutation in a regulatory element located within the HERC2 gene inhibiting OCA2 expression. Hum. Genet. 2008, 123, 177-187. [CrossRef] [PubMed]

3. Tassini, G. As quoted by Konrad Bloch in "Blondes in Venetian Paintings"; Yale University Press: New Haven, CT, USA, 1988.

4. Wolfram, L.J.; Albrect, L. Chemical and photo-bleaching of brown and red hair. J. Soc. Cosmet. Chem. 1987, 38, 179-191.

5. Wolfram, L.J.; Maibach, H. Percutaneous penetration hair dyes. Arch. Dermatol. Res. 1985, 277, $235-241$. [CrossRef] [PubMed]

6. McGinnes, J.; Proctor, P. The importance of the fact that melanin is black. J. Theor. Biol. 1973, 39, 677-678. [CrossRef]

7. Kurz, S.K.; Kozikowski, S.D.; Wolfram, L.J. Nonlinear optical and electrooptical properties of biopolymers. In Proceedings of the International School on Material Science and Technology, Erice, Italy, 6-17 July 1986.

8. Kurz, S.K.; Bohren, C.; Wolfram, L.J.; Albrecht, L. Further advances toward a quantitative, predictive physical model of hair color. In Proceedings of the 1st PanAmerican Pigment Cell Biology Meeting, Minneapolis, MN, USA, 24-26 June 1985.

9. Staudinger, H. Über polymerization. Ber. Deut. Chem. Gesel. 1920, 53, 1073-1091. [CrossRef]

10. Mark, H.; Astbury, W.T. Physics of Fibers; Woods, H.J., Ed.; The Institute of Physics: London, UK, 1955; pp. 30-46.

11. Asbury, W.T.; Sisson, W.A. X ray studies of the structure of hair, wool and related fibres. Proc. R. Soc. (Phys.) 1935, 150, 533-545. [CrossRef]

12. Woods, H.J. The molecular structure and elastic properties of the biological cells. Proc. R. Soc. (Phys.) 1938, 168, 76-85. [CrossRef]

13. Speakman, J.B. The reactivity of the sulfur linkage in animal fibres. J. Soc. Dyers Colour. 1936, 52, 380-389. [CrossRef]

14. Harris, M. Role of cystine in the structure of the fibrous proteins-wool. J. Res. Nat. Bur. Stand. 1941, 27, 89-94.

15. Zahn, H. Ueber thermisch-verkuerzte keratinfasern. Naturwissenschaften 1943, 31, 137-139. [CrossRef]

16. Wolfram, L.J.; Lindemann, K.O. Some observations on the hair cuticle. J. Soc. Cosmet. Chem. 1971, 22, 839-850.

17. Feughelman, M. Mechanical Properties and Structure of Alpha-Keratin Fibres: Wool, Human Hair and Related Fibres; Madjar, N., Ed.; University of New South Wales Press: Sydney, Australia, 1997; pp. 37-40.

18. Wortmann, F.J.; Kure, N. Bending relaxation properties of human hair and permanent waving performance. J. Soc. Cosmet. Chem. 1990, 41, 123-125.

19. Feughelman, M. Mechanical Properties and Structure of Alpha-Keratin Fibres: Wool, Human Hair and Related Fibres; Madjar, N., Ed.; University of New South Wales Press: Sydney, Australia, 1997; pp. 95-99.

20. Wolfram, L.J.; Underwood, D.L. The equilibrium between the disulfide linkage in hair keratin and sulfite or mercaptan. Text. Res. J. 1966, 36, 947-962. [CrossRef]

21. Wolfram, L.J. Exploratory Experimentation on Waving Efficacy. (Unpublished observation).

22. Maclaren, J.A.; Milliigan, B. Wool Science; Science Press: Beijing, China, 1981; pp. 99-102.

23. Wong, M.; Wis-Surel, G.; Epps, J. Mechanism of hair straightening. J. Soc. Comet. Chem. 1944, 45, 347-352.

24. Wolfram, L.J. On straightening and relaxing of African hair. J. Cosmet. Sci. 2015, 66, 207-210. [PubMed]

25. Wolfram, L.J. Human Hair: A unique physicochemical composite. J. Acad. Dermatol. 2003, 48, 347-352. [CrossRef] [PubMed]

26. Speakman, J.B.; Nichols, C.H. The adsorption of water by wool. The influence of combined acid on the affinity of wool for water. J. Text. Inst. Trans. 1954, 45, T267-T271.

27. Klotz, I.M. Role of the water structure on macromolecules. Proc. Fed. Am. Soc. Expt. Biol. 1965, 15, 5-24. 
28. Nemethy, G. Hydrophobic interactions. Angew. Chem. Int. Ed. 1967, 6, 195-201. [CrossRef] [PubMed]

29. Hall, K.; Wolfram, L.J. Application of the theory of hydrophobic bonds to hair treatments. J. Soc. Comet. Chem. $1977,28,231-241$.

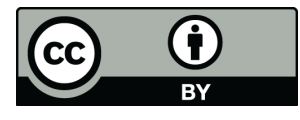

(C) 2016 by the author; licensee MDPI, Basel, Switzerland. This article is an open access article distributed under the terms and conditions of the Creative Commons Attribution (CC-BY) license (http://creativecommons.org/licenses/by/4.0/). 